\title{
Molecular Screening of Adhesion Proteins Genes in Staphylococcus aureus Strains Isolated from Different Clinical Infections in Baghdad City and Identification of Their Relationship with Some Virulence Factors
}

\author{
Aalaa Theyab Ahmed Al Ani ${ }^{*}$ and Safaa Abed Lateef Al Meani \\ Department of Biology, College of Science, University of Anbar. \\ ${ }^{*}$ Corresponding Author: bioflower100@gmail.com.
}

\begin{abstract}
The first step to achieve Staphylococcus aureus infections is the adhesion process that is mediated by proteins belong to the microbial surface component recognizing adhesive matrix molecules (MSCRAMMs). The distribution of these proteins is different among S. aureus isolates. In Iraq, there are no previous studies have been done in regard of distribution of these important virulence factors. Therefore, this study was designed to use PCR for screening of MSCRAMMs genes among local $S$. aureus isolates and determination of some virulence factors. $S$. aureus isolates (32) were collected from different hospitals in Baghdad and were diagnosed by conventional methods (cultural methods, colony morphology, Gram stain and biochemical tests). API Staph. System was used to confirm the diagnosis. Antimicrobial susceptibility test was performed by disc diffusion method for ten antibiotics. The ability to produce some virulence factors by bacterial isolated was detected [hemolysis activity, Deoxy ribonuclease (DNase) production and biofilm production]. The diagnosis of bacterial isolates was super-confirmed using PCR to detect the nuc gene. Uniplex and multiplex PCR were used to detect the MSCRAMMs genes (Uniplex PCR was used to detect $f n b A$ and $c n a$ genes (each alone). multiplex PCR were used to detect $b b p$ and $e b p$ genes in one run and $c l f A, c l f B, f i b$ and $f n b B$ genes in other run. All isolates were diagnosed as $S$. aureus (were negative to oxidase. Positive to catalase, slide and tube coagulase and Ferment mannitol). All isolates were recorded as $S$. aureus by API Staph system. A high prevalence of MRSA strains $(78 \%)$ was detected, vancomycin and imipenem were the most affected with percentage $(97 \%)$ and $(94 \%)$ respectively; results of susceptibility to other antibiotics was variant. Beta hemolysis was detected in $(65.6 \%)$ of isolates, $34.4 \%$ of isolates did not give any zone (gamma hemolysis), while no alpha hemolysis have been detected. On the other hand, all isolates (100\%) produced DNase enzyme. The results of biofilm production assay shown that $40.6 \%$ of strains gave a weak positive results. The results shown that all isolates $(100 \%)$ that were diagnosed as $S$. aureus by traditional methods harbored the $n u c$ gene. The distribution percentage of $b b p$, $e b p$, clfA, clfB, cna, fib, fnbA and fnbB were $21.9 \%, 90.6 \%, 100 \%, 81.3 \%, 93.8 \%, 96.9 \%, 100 \%$ and $25 \%$ respectively. The distribution of adhesive genes are variant among $S$. aureus isolates and the infection sources. The $b b p$ is the most specific infection associated gene with osteomyelitis.

[DOI: $10.22401 / \mathrm{JUNS} .21 .1 .13$ ]
\end{abstract}

Keywords: S. aureus, Surface adhesion proteins, Virulence factors, PCR.

\section{Introduction}

Staphylococcus aureus is a dangerous opportunistic pathogen that known to colonize the human nares, skin, and gastrointestinal tract. Colonization increases risk for developing of infections (1). S. aureus is a leading cause of a numerous different diseases in both community and nosocomial environments such as skin and soft tissue infections, bacteremia, endocarditis, pneumonia, toxic shock syndrome, scalded skin syndrome and osteomyelitis. S. aureus strains requires an arsenal of virulence factors for an infection promotion; these virulence factors facilitate tissue adhesion, escape from innate immune responses, tissue and cellular damage and impair connective tissues (2).

The microbial surface components recognizing adhesive matrix molecules (MSCRAMMs) are important virulence factors of $S$. aureus that mediate the initiation of attachment to both native tissues and biomaterials surface. They are many specific proteins on microbe surface, each is specialized to one or more than one specific host receptors and mediates adhering to the 
extracellular matrix leading to colonization of the host "first step of infection" MSCRAMMs act also as a critical factor to biofilm formation (3). Moreover, these molecules directly affect host cell signaling to aid bacterial spread and survival. Adhesion also helps the pathogen survive the pervasive fluid (shear) force present in the host (4). Atypical members of the MSCRAMMs family are bone sialoprotein binding protein (Bbp), elastin binding proteins (Ebp), clumping factor (Clf) A and B, collagen binding protein ( $\mathrm{Cna})$, fibrinogen binding proteins (Fib) and fibronectin binding proteins $\mathrm{A}$ and $\mathrm{B}$ (FnbpA and FnbpB) that encoded by $b b p$, ebp, clfA, clfB, cna, fib, fnbA and $f n b B$ respectively.

Staphylococcal biofilm formation are functionally resistant to the immune system components and antibiotics. Development of antimicrobial resistance reduces responsive to treatment of this bacterium, these often lifethreatening infections (5).

Detection of MSCRAMMs proteins by using binding test with purified matrix molecules does not has high specificity. For example, all of ClfA, ClfB and Fib bind to same matrix molecules (fibrinogen); also two kinds of proteins (A and B) of Clf and Fnbp are present. Furthermore, some of these proteins bind to more than one target matrix such as Fnbps binds to fibronectin, fibrinogen and elastin (6). On the other hand, this method required high cost for purification.

For all above, the aim of this study is to use the conventional PCR to identify, determine the distribution of adhesive proteins (MSCRAMMs) genes in local Staphylococcus aureus isolates and their relationship with biofilm formation and MRSA strains.

\section{Materials and Methods Identification of bacterial isolates}

From different hospitals in Iraq-Baghdad including ( Ibn Al Bitar, Al Wasity, Al Yarmouk, Al-Nu'man, Baghdad and Educational laboratories in medical city), a total of $32 \mathrm{~S}$. aureus clinical isolates were collected from different infection sources including: wounds inflammations (5), burns (4), osteomyelitis (5), endocarditis (5), pneumonia (4), abscesses (4) and nose (5) from July 2016 to November 2016. The specimens were cultured on 5\% blood agar and MacConkey agar. The isolates were identified with colony morphology, gram stain, cultural methods and biochemical tests, such as catalase, oxidase, mannitol fermentation on Mannitol Salt Agar (MSA) medium, slide and tube coagulase tests, DNase production and API Staph system (biomerieux-France).

\section{Antibiotics susceptibility test}

The disk diffusion testing was used in this study according to Bauer method and CLSI standard $(7,8)$. Ten antibiotic agents were tested against $S$. aureus. They were amikacin, cefotaxime, ciprofloxacin, clindamycin, erythromycin, imipenem, oxacillin, penicillin, tetracycline and vancomycin. The bacterial inoculum was diluted and adjusted to 0.5 McFarland standard, then it was spread on Muller Hinton agar by swab that was slanted at $45^{\circ}$ with the plates surface. After incubation at $35^{\circ} \mathrm{C}$ for $24 \mathrm{~h}$, inhibition zone diameter in millimeters was recorded. Finally, these data were compared with the standard inhibition zone of CLSI (8).

\section{Detection of biofilm production}

The microtiter plate of biofilm production assay was used depending on procedures that were described by Christensen et al., 1985 (9).

\section{Primers design}

All 9 genes sequences were obtained from Gen Bank/NCBI. Multiplex Polymerase primer (MP primer) program was used for primers design and the outputs of this program were conformed with previous studies "which were mentioned by Peacock et al., 2002; Tristan et al., 2003 and Karmakar et al., 2016" $(10,11,12)$. The primers were synthesized by (Eurofins Genomic, Germany), Table (1).

\section{Extraction of genomic DNA}

Each bacterial isolate was grown in brain heart infusion broth for $20 \mathrm{~h}$ in an aerobic condition with shaking $(150 \mathrm{rpm})$ at $37^{\circ} \mathrm{C}$. The growth cultures were precipitated in $1.5 \mathrm{ml}$ tubes by micro centrifuge at $14500 \mathrm{rpm}$ for 2 min. Finally the pellets were used for genomic DNA extraction according to manufacturer recommendation (Geneaid "presto", Korea). 
Estimation of DNA purity and concentration

The Nano-drop device (NAS-99) was used to measure the DNA concentration and purity (absorption at $260 \mathrm{~nm} /$ absorption at $280 \mathrm{~nm}$ ).

\section{Molecular identification of $S$. aureus strains} by uniplex-PCR amplification of nuc gene

The amplification was performed in a Thermal Cycler (Bioneer, Korea) by using a thin wall blue master-mix eppendrof tube that contains $5 \mu \mathrm{L}$ of lypholized mixture (Bioneer "PCR premix", Korea). Other contents were added $(1 \mu \mathrm{L}$ of forward primer $(10 \mathrm{Pm} / \mu \mathrm{L}), 1$ $\mu \mathrm{L}$ of reverse primer $(10 \mathrm{Pm} / \mu \mathrm{L})$, DNA template (60 ng) and DNase-RNAse free deionized distilled water to complete the volume to $20 \mu \mathrm{L}$ without master mix calculation). Primers and the thermal cycling conditions were described in Table (1) and (2) respectively.

\section{Detection of $c n a$ and $f n b A$ genes by uniplex- PCR}

Each one of these genes was detected alone by using single PCR. The addition conditions and volumes used were similar to that in $n u c$ reaction. Primers and the thermal cycling conditions were described in Table (1) and (2) respectively.

Table (1)

Primers' sequences used in this study and their information.

\begin{tabular}{|c|c|c|c|c|c|c|}
\hline Gene & Primers' Sequences $\left(5^{\prime} \rightarrow 3^{\prime}\right)$ & $\begin{array}{l}\operatorname{Tm} \\
\left({ }^{\circ} \mathrm{C}\right) \\
\end{array}$ & Product size (bp) & $\begin{array}{c}\text { Accession } \\
\text { no. }\end{array}$ & \begin{tabular}{|c|}
$\begin{array}{c}\text { Gene size } \\
(\mathrm{bp})\end{array}$ \\
\end{tabular} & Reference \\
\hline \multirow{2}{*}{$b b p$} & F:AACTACATCTAGTACTCAACAACAG & 58.1 & \multirow{2}{*}{575} & \multirow{2}{*}{ Y18653 } & \multirow{2}{*}{3515} & \multirow{2}{*}{11} \\
\hline & R:ATGTGCTTGAATAACACCATCATCT & $\begin{array}{l}58.1 \\
\end{array}$ & & & & \\
\hline \multirow{2}{*}{ clfA } & F:ATTGGCGTGGCTTCAGTGCT & $\begin{array}{c}59.4 \\
\end{array}$ & \multirow{2}{*}{292} & \multirow{2}{*}{ Z18852 } & \multirow{2}{*}{2801} & \multirow{2}{*}{11} \\
\hline & R:CGTTTCTTCCGTAGTTGCATTTG & 58.9 & & & & \\
\hline \multirow{2}{*}{$c l f B$} & F:ACATCAGTAATAGTAGGGGGCAAC & 61.0 & \multirow{2}{*}{205} & \multirow{2}{*}{ AJ22476 } & \multirow{2}{*}{2742} & \multirow{2}{*}{11} \\
\hline & R:TTCGCACTGTTTGTGTTTGCAC & 58.4 & & & & \\
\hline \multirow{2}{*}{ cna } & F:AGTGGTTACTAATACTG & 45.5 & \multirow{2}{*}{$\begin{array}{l}\text { Polymorphism } \\
(617,1178,1739)\end{array}$} & \multirow{2}{*}{ M81736 } & \multirow{2}{*}{3565} & \multirow{2}{*}{10} \\
\hline & R:CAGGATAGATTGGTTTA & 45.5 & & & & \\
\hline \multirow[b]{2}{*}{$e b p$} & F:CATCCAGAACCAATCGAAGAC & 57.9 & \multirow[b]{2}{*}{186} & \multirow[b]{2}{*}{$\mathrm{U} 48826$} & \multirow[b]{2}{*}{1461} & \multirow[b]{2}{*}{ This study } \\
\hline & $\begin{array}{l}\text { R:CTTAACAGTTACATCATCATGTTTATC } \\
\text { TT }\end{array}$ & 58.2 & & & & \\
\hline \multirow{2}{*}{$f i b$} & F:CTACAACTACAATTGCCGTCAACAG & 61.3 & \multirow{2}{*}{404} & \multirow{2}{*}{ X72014 } & \multirow{2}{*}{794} & \multirow{2}{*}{1} \\
\hline & R:GCTCTTGTAAGACCATTTTCTTCAC & 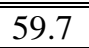 & & & & \\
\hline \multirow{2}{*}{$f n b A$} & F:CACAACCAGCAAATATAG & 499.1 & \multirow{2}{*}{1362} & \multirow{2}{*}{$\begin{array}{c}\text { NC00779 } \\
5\end{array}$} & \multirow{2}{*}{2973} & \multirow{2}{*}{10} \\
\hline & R:CTGTGTGGTAATCAATGTC & 52.4 & & & & \\
\hline \multirow{2}{*}{$f n b B$} & F:GTAACAGCTAATGGTCGAATTGATACT & 60.4 & 524 & & 2891 & 11 \\
\hline & R:CAAGTTCGATAGGAGTACTATGTTC & 59.7 & 524 & $\times 62992$ & 2891 & 11 \\
\hline nuc & F:GCGATTGATGGTGATACGGTT & $\begin{array}{c}57.9 \\
\end{array}$ & 278 & DQ50738 & 682 & 2 \\
\hline пис & | R:AGCCAAGCCTTGACGAACTAAAGC & 62.7 & & 2 & 682 & 12 \\
\hline
\end{tabular}

Detection of $b b p, e b p, c l f A, c l f B, f i b$, and fnbB genes by multiplex PCR

Both $b b p$ and $e b p$ genes were detected in one multiplex PCR run, while all clfA, clfB, $f i b$, and $f n b B$ were detected in other multiplex PCR run. The conditions of both these runs were similar: The reactions was performed using a thin wall green master-mix eppendrof tube that contains $5 \mu \mathrm{L}$ of lypholized mixture (Bioneer "Gold Multiplex PCR premix",
Korea). Other contents were added $[0.5 \mu \mathrm{L}$ of forward primer $(10 \mathrm{Pm} / \mu \mathrm{L})$ for each gene, $0.5 \mu \mathrm{L}$ of reverse primer $(10 \mathrm{Pm} / \mu \mathrm{L})$ for each gene, DNA template (100 ng) and DNaseRNAse free deionized distilled water to complete the volume to $20 \mu \mathrm{L}$ without master mix calculation]. Primers and the thermal cycling conditions were described in Table (1) and 2 respectively. 
Table (2)

The thermal cycling conditions.

\begin{tabular}{|c|c|c|c|c|c|c|c|c|c|c|c|}
\hline \multirow{3}{*}{ Genes } & \multirow{2}{*}{\multicolumn{2}{|c|}{$\begin{array}{c}\text { Initial } \\
\text { Denaturation }\end{array}$}} & \multicolumn{6}{|c|}{$\overline{\text { Each cycle }}$} & \multirow{3}{*}{$\begin{array}{c}\text { Cycles } \\
\text { no. }\end{array}$} & \multirow{2}{*}{\multicolumn{2}{|c|}{ Terminated }} \\
\hline & & & \multicolumn{2}{|c|}{ Denaturation } & \multicolumn{2}{|c|}{ Annealing } & \multicolumn{2}{|c|}{ Extension } & & & \\
\hline & $\begin{array}{l}\text { Temp. } \\
\left(C^{\circ}\right)\end{array}$ & $\begin{array}{l}\text { Time } \\
(\mathrm{min})\end{array}$ & $\begin{array}{l}\text { Temp. } \\
\left(C^{\circ}\right)\end{array}$ & $\begin{array}{l}\text { Time } \\
\text { (min) }\end{array}$ & $\begin{array}{l}\text { Temp. } \\
\left(C^{\circ}\right)\end{array}$ & $\begin{array}{l}\text { Time } \\
\text { (min) }\end{array}$ & $\begin{array}{l}\text { Temp. } \\
\left(C^{\circ}\right)\end{array}$ & $\begin{array}{l}\text { Time } \\
\text { (S.) }\end{array}$ & & $\begin{array}{l}\text { Temp. } \\
\left(C^{\circ}\right)\end{array}$ & $\begin{array}{l}\text { Time } \\
\text { (min) }\end{array}$ \\
\hline nuc & 94 & $\overline{5}$ & 94 & $\overline{1}$ & 55 & $\overline{1}$ & 72 & $\overline{30}$ & 25 & 72 & 10 \\
\hline$f n b A$ & 94 & $\overline{5}$ & 94 & $\overline{11}$ & $\overline{50}$ & $\overline{c 1}$ & 72 & 120 & 30 & 72 & 10 \\
\hline cna & 94 & $\overline{5}$ & 94 & 1 & 52 & 1 & 72 & 120 & 30 & 72 & 10 \\
\hline $\begin{array}{c}\text { bbp, } \\
\text { ebp, fib, } \\
\text { fnbB, } \\
\text { clfA } \\
\text { and } \\
\text { clfB }\end{array}$ & 94 & 5 & 94 & 1 & 55 & 1 & 72 & 60 & 25 & 72 & 10 \\
\hline
\end{tabular}

\section{Detection of DNA bands by electrophoresis}

For genomic DNA bands, agarose gel (1\%) was used in electrophoresis for $1 \mathrm{~h}$ with 80 volt. For PCR products' bands, agarose gel $(1.5 \%)$ was used for $1.5-2 \mathrm{~h}$ with 70 volt.

\section{Statistical analysis}

Chi square test was used for determination of association of MSCRAMMs genes with infections sources and relationship of these genes with biofilm production ability and with MRSA strains. Moreover, relationship between biofilm production ability and methicillin resistance ability.

\section{Results and Discussion \\ Identification of bacterial isolates}

All selected isolates didn't grow on MacConkey agar, they grew on blood agar (5\%) with opaque, round, smooth, raised, 1 to $3 \mathrm{~mm}$ in diameter and glistening colonies. When isolated, cells were stained by Gram stain, they appeared as Gram positive cocci. All 32 isolates gave positive results for mannitol fermentation, slide and tube coagulase tests; while all these isolates gave negative results for oxidase test. Thirty two isolates were detected as S. aureus by API Staph system. All 32 selected isolates produced DNase by appearance of a clear zone around the colonies on DNase agar after flooding by $(0.1 \mathrm{~N}) \mathrm{HCl}$. On $5 \%$ blood agar, twenty one $(65.6 \%)$ isolates produced $\beta$-hemolysis zones. Eleven (34.4\%) isolates didn't produce any zone (gamma- hemolysis); Table (3).

\section{Antibiotics susceptibility test}

Results of antibiotic susceptibility test were explained in Fig.(1). A variant susceptibility for antimicrobial agents was detected. Twenty five isolates $(78 \%)$ were obtained as a methicillin resistant $S$. aureus (MRSA) depending on obtained of oxacillin resistant $S$. aureus (ORSA) by oxacillin disk diffusion.

Vancomycin and Imipenem "both antibiotics effect on cell wall of bacterial cells" are the strongest anti $S$. aureus agents were 31 $(97 \%)$ tested isolates were sensitive to vancomycin, 30 isolates (94\%) were sensitive to Imipenem and 1 isolates (3\%) appeared as vancomycin intermediate resistant $S$. aureus (VISA).

On the other hand, penicillin and cefotaxime had the lowest affect (3\%). Other antibiotics had variant influences among different isolates but from interest that 21 isolates $(66 \%)$ expressed intermediate resistance to cefotaxime.

The high oxacillin resistance obtaining in this study is considered risky indicator to spread MRSA strains in local Iraqi isolates. Results of oxacillin susceptibility test are sufficient to investigation of the mecA presence, therefore all ORSA is MRSA in the same time. PBP2a is a recent penicillin binding protein that is encoded by this gene. By this property, the MRSA strain can resist of all beta lactam (13). That is the same cause to high resistance to penicillin $(97 \%)$ where all MRSA isolates in this study were penicillin 
resistant. In addition to $\beta$-lactam, MRSA isolates resist to many of the tested antibiotic and appeared as a Multi-drug Resistant. That leads to complicate the treatment of this infections. MRSA strains can have resistance genes on plasmids and in other genome spot in addition to those in the $\mathrm{SCCmec}$, that explains the cause of multi antibiotic resistant in these strains. Resistance of these antibiotic occurs by different mechanisms such as chemical modification, ribosomal protection, and efflux pump (14).

Table (3)

Biochemical tests and some virulence factors.

\begin{tabular}{|c|c|c|c|c|c|c|c|c|c|c|c|c|}
\hline \multirow{3}{*}{ Isolates sources } & \multicolumn{12}{|c|}{ Biochemical tests and some virulence factors } \\
\hline & \multicolumn{2}{|c|}{ Oxidase } & \multicolumn{2}{|c|}{ Catalase } & \multicolumn{2}{|c|}{ Coagulase } & \multicolumn{2}{|c|}{ DNase tests } & \multicolumn{2}{|c|}{ Haemolysis } & \multicolumn{2}{|c|}{$\begin{array}{c}\text { Mannitol } \\
\text { fermentation }\end{array}$} \\
\hline & + & - & + & - & + & - & + & - & $\beta$ & - & + & - \\
\hline Abscesses (4) & 0 & 4 & 4 & 0 & 4 & 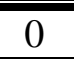 & 4 & $\overline{0}$ & 3 & 1 & 4 & 0 \\
\hline Burns (4) & 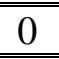 & 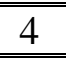 & 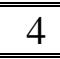 & 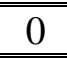 & \begin{tabular}{c|}
4 \\
\end{tabular} & 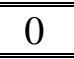 & $\begin{array}{l}4 \\
\end{array}$ & 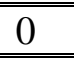 & 3 & 1 & 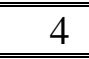 & 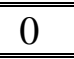 \\
\hline Carditis (5) & 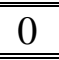 & 5 & 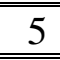 & 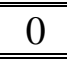 & 5 & 0 & 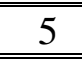 & 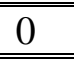 & 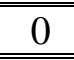 & 5 & 5 & 0 \\
\hline Nose (5) & 0 & 5 & 5 & 0 & 5 & 0 & 5 & 0 & 3 & 2 & 5 & 0 \\
\hline Osteomy. (5) & 0 & 5 & 5 & 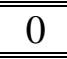 & 5 & 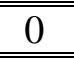 & 5 & 0 & 4 & 1 & 5 & 0 \\
\hline Pneumonia (4) & 0 & 4 & 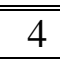 & 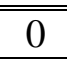 & 4 & 0 & 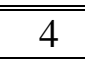 & 0 & 4 & 0 & 4 & 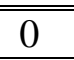 \\
\hline Wounds (5) & 0 & 5 & 5 & 0 & 5 & 0 & 5 & 0 & 4 & 1 & 5 & 0 \\
\hline$\sum$ of $(+\mathrm{Ve})$ & \multicolumn{2}{|c|}{0} & \multicolumn{2}{|c|}{32} & \multicolumn{2}{|c|}{32} & \multicolumn{2}{|c|}{32} & \multicolumn{2}{|c|}{21} & \multicolumn{2}{|c|}{21} \\
\hline$\%$ of $(+\mathrm{Ve})$ & \multicolumn{2}{|c|}{$0 \%$} & \multicolumn{2}{|c|}{$100 \%$} & \multicolumn{2}{|c|}{$100 \%$} & \multicolumn{2}{|c|}{$100 \%$} & \multicolumn{2}{|c|}{$65.6 \%$} & \multicolumn{2}{|c|}{$100 \%$} \\
\hline
\end{tabular}

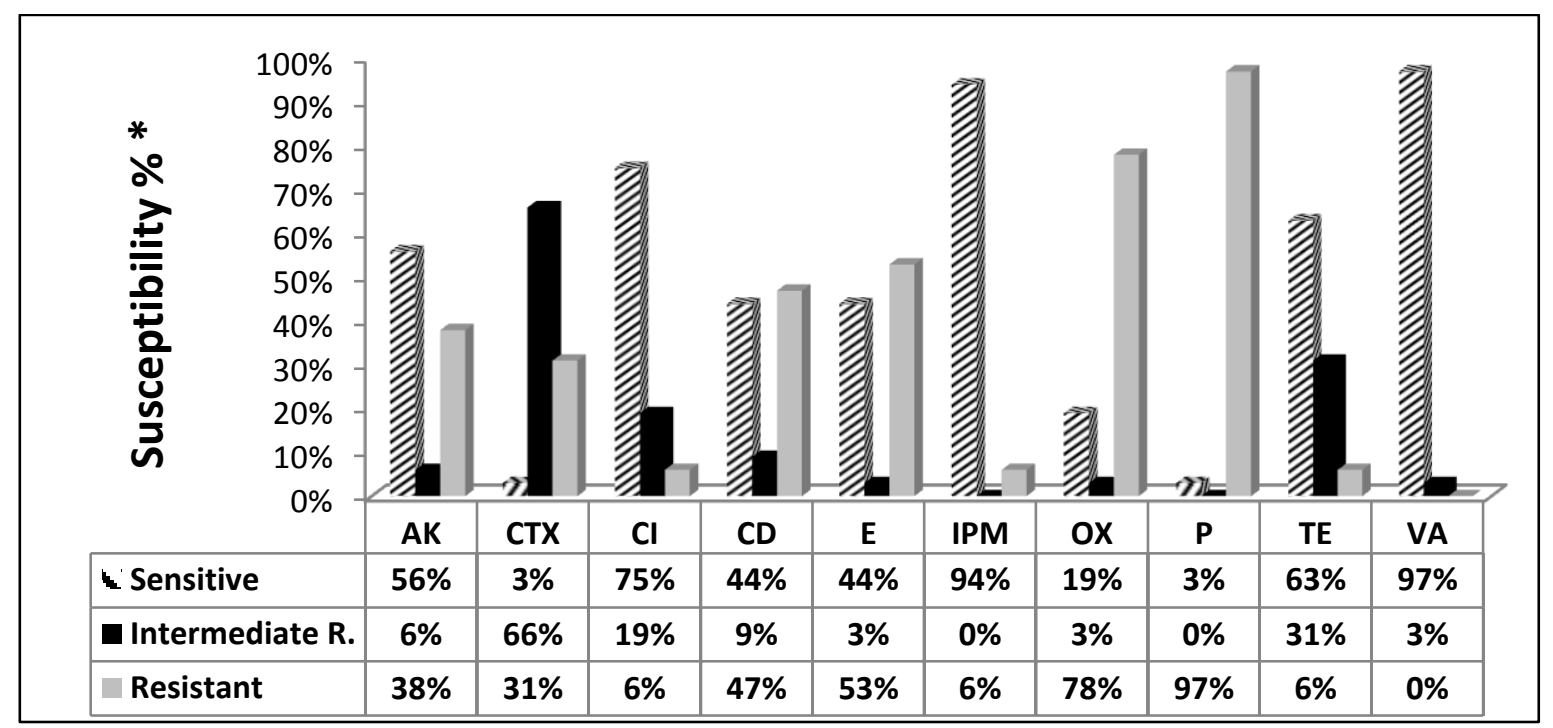

Fig.(1): Antibiotics susceptibility test; AK: amikacin, CTX: cefotaxime, CI: ciprofloxacin, CD: clindamycin, $E$ : erythromycin, IPM: imipenem, $O X$ : oxacillin, P: penicillin, TE: tetracycline and VA: vancomycin. *: the percentage values were approximated to the nearest integer.

\section{Biofilm production}

Thirteen isolates $(41 \%)$ gave a weak positive results for biofilm production test Fig.(2). The weak biofilm formation ability was high related with MRSA strains. In addition to the multi drug resistance recorded, the biofilm former $S$. aureus isolates are the most difficult in treatment due to many resting cells are agglomerated within the matrix of biofilm. Extracellular matrix provides protective barrier against antimicrobial agent, reducing their permeability into the biofilm (5). A gathering of multi-drugs resistance and ability of biofilm production increases the problem. 


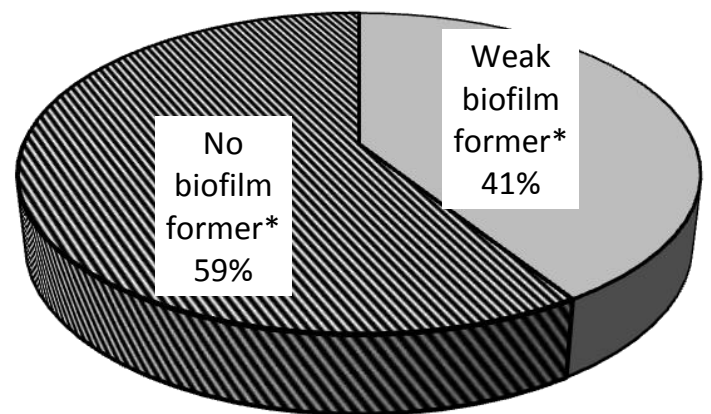

Fig.(2): Results of biofilm production test, *: the percentage values were approximated to the nearest integer.

\section{Extraction of genomic DNA and estimation of its purity and concentration}

DNA bands appeared in the extraction outputs of all samples with high concentration and typical purity. for all isolates, Nano-drop data ranged (1.81-2.0) for DNA purity and $(60.1-250) \mathrm{ng} / \mu \mathrm{L}$ for DNA concentration.
Molecular identification of $S$. aureus strains by uniplex PCR Amplification of nuc gene

The nuc gene was found in all isolates $(100 \%)$ with a PCR product size of $270 \mathrm{bp}$ isolates Fig.(3) and Table (4). The nuc gene "which express thermostable nuclease" is a specific gene for S. aureus (15). Therefore, the detection of $n u c$ gene in all isolates of this study provides high accuracy in isolation of $S$. aureus and confirm its diagnosis in this study. Where diagnosis of $S$. aureus by detection of nuc gene is more accurate than biochemical and cultural ways; but in our study, we did not notice any differences between the genetic diagnosis and the diagnosis by conventional methods. that may occurred because that all 32 isolates "which identified by PCR of nuc gene" were positive for DNase production test, coagulase test and API Staph system. Therefore, all isolates that expressed the deoxy ribonuclease enzyme (DNase) have nuc gene.

Table (4)

Results of Molecular detections.

\begin{tabular}{|c|c|c|c|c|c|c|c|c|c|c|c|c|c|c|c|c|c|c|}
\hline \multirow{3}{*}{$\begin{array}{l}\text { Isolates } \\
\text { sources }\end{array}$} & \multicolumn{18}{|c|}{ Molecular detections } \\
\hline & \multicolumn{2}{|c|}{ nuc } & \multicolumn{2}{|c|}{ bbp } & \multicolumn{2}{|c|}{$e b p$} & \multicolumn{2}{|c|}{ clfA } & \multicolumn{2}{|c|}{ clfB } & \multicolumn{2}{|c|}{ cna } & \multicolumn{2}{|c|}{ fib } & \multicolumn{2}{|c|}{$f n b A$} & \multicolumn{2}{|c|}{$f n b B$} \\
\hline & + & - & + & - & + & - & + & - & + & - & + & - & + & - & + & - & + & - \\
\hline Abscesses(4) & 4 & 0 & 0 & 4 & 4 & 0 & 4 & 0 & 3 & 1 & 4 & 0 & 4 & 0 & 4 & 0 & 2 & 2 \\
\hline Burns(4) & 4 & 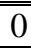 & 1 & 3 & 2 & 2 & 4 & 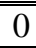 & 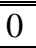 & 4 & 3 & 1 & 3 & 1 & 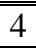 & 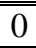 & 1 & 3 \\
\hline Carditis(5) & 5 & 0 & 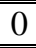 & 5 & 4 & 1 & 5 & 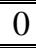 & 5 & 0 & 5 & 0 & 5 & 0 & 5 & 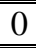 & 1 & 4 \\
\hline Nose(5) & 5 & 0 & 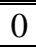 & 5 & $\overline{5}$ & 0 & 5 & 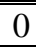 & 4 & 1 & 4 & 1 & 5 & 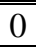 & $\overline{5}$ & 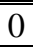 & 1 & 4 \\
\hline "Osteomy. (5) & $\overline{5}$ & $\overline{00}$ & $\overline{5} 5$ & 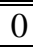 & $\bar{~} 5$ & 0 & $\overline{25}$ & 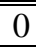 & $\overline{5}$ & 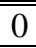 & $\bar{~} 5$ & 0 & 5 & 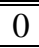 & $\overline{5} 5$ & 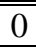 & 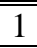 & $\overline{4}$ \\
\hline Pneumonia(4) & 4 & 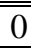 & 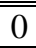 & 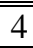 & 4 & 0 & 4 & 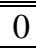 & 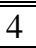 & 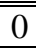 & 4 & 0 & 4 & 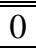 & 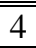 & 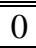 & 1 & 3 \\
\hline Wounds (5) & $\overline{5}$ & 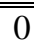 & 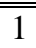 & 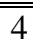 & $\overline{5}$ & 0 & $\overline{5}$ & 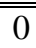 & $\overline{5}$ & 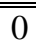 & $\overline{5}$ & 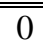 & 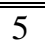 & 0 & $\overline{5}$ & 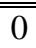 & 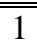 & 4 \\
\hline$\sum$ of $(+V e)$ & \multicolumn{2}{|c|}{32} & \multicolumn{2}{|c|}{7} & \multicolumn{2}{|c|}{29} & \multicolumn{2}{|c|}{32} & \multicolumn{2}{|c|}{26} & \multicolumn{2}{|c|}{30} & \multicolumn{2}{|c|}{31} & \multicolumn{2}{|c|}{32} & \multicolumn{2}{|c|}{4} \\
\hline$\%$ of $(+\mathrm{Ve})$ & \multicolumn{2}{|c|}{100} & \multicolumn{2}{|c|}{21.9} & \multicolumn{2}{|c|}{90.6} & \multicolumn{2}{|c|}{100} & \multicolumn{2}{|c|}{81.3} & \multicolumn{2}{|c|}{93.8} & \multicolumn{2}{|c|}{96.9} & \multicolumn{2}{|c|}{100} & \multicolumn{2}{|c|}{25} \\
\hline
\end{tabular}

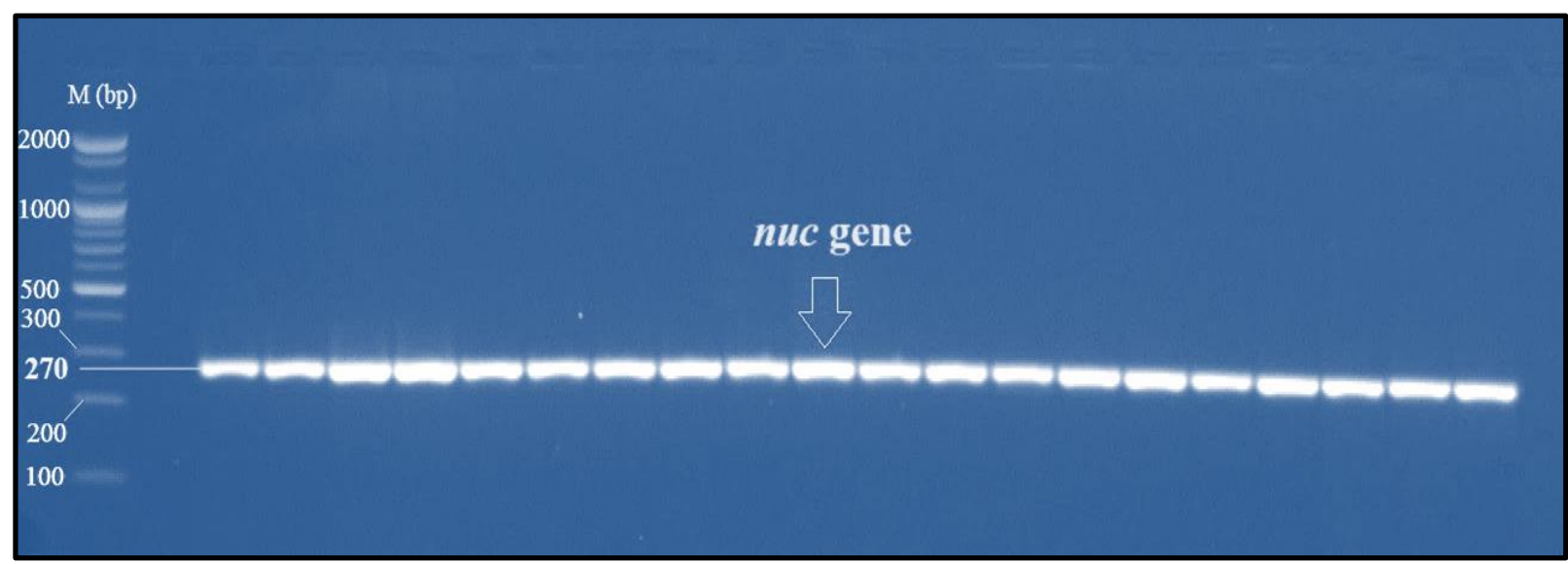

Fig.(3): Uniplex PCR amplification of nuc gene [1.5\% agarose, 1.5-2 h, $70 \mathrm{~V}$ ] with end product size (270 bp); M: molecular weight marker. 
Detection of adhesions encoding genes (cna, $f n b A, f n b B, b b p, e b p, f i b, c l f A$ and clfB)

The $f n b A$ gene was detected in all the isolates (100\%) Fig.(4) and Table (4). While the cna gene was detected in $30(93.8 \%)$ isolates Fig.(5) and Table (4).

The prevalence of $b b p$ and $e b p$ genes was 7 (21.9\%) and 29 (90.6\%) respectively Fig.(6) and Table (4). The prevalence of clfA, clfB, fib and $f n b B$ was $32(100 \%), 26(81.3 \%), 31$ (96.9\%) and 8 (25\%) respectively Fig.(7) and Table (4).

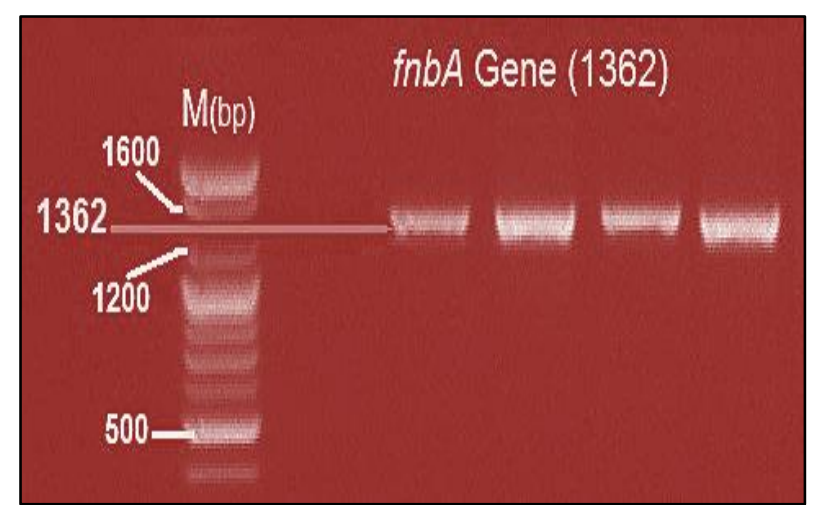

Fig.(4): Uniplex PCR amplification of fnbA gene [1.5\% agarose, 1.5-2 $h$ and $70 \mathrm{~V}]$ with end product size (1362 bp); M: molecular weight marker.

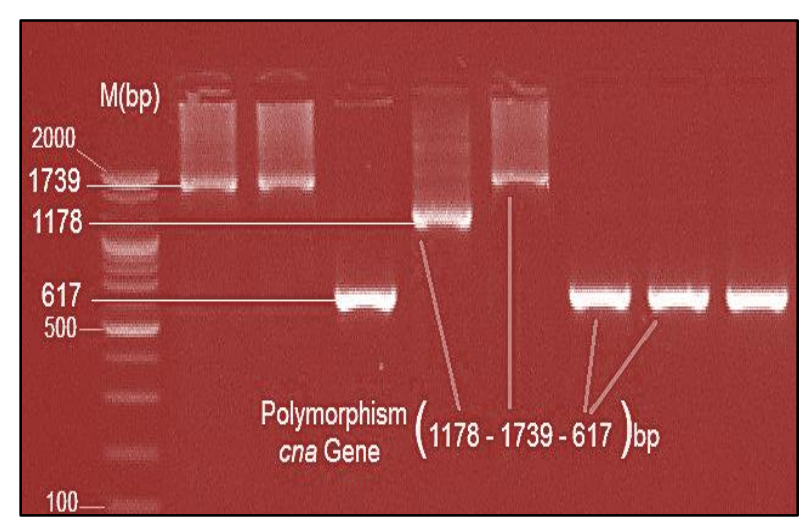

Fig.(5): Uniplex PCR amplification of cna gene [1.5\% agarose, 1.5-2 $\mathrm{h}$ and $70 \mathrm{~V}$ ] with multi-end product sizes: $(617,1178$ and 1739) bp; M: molecular weight marker.

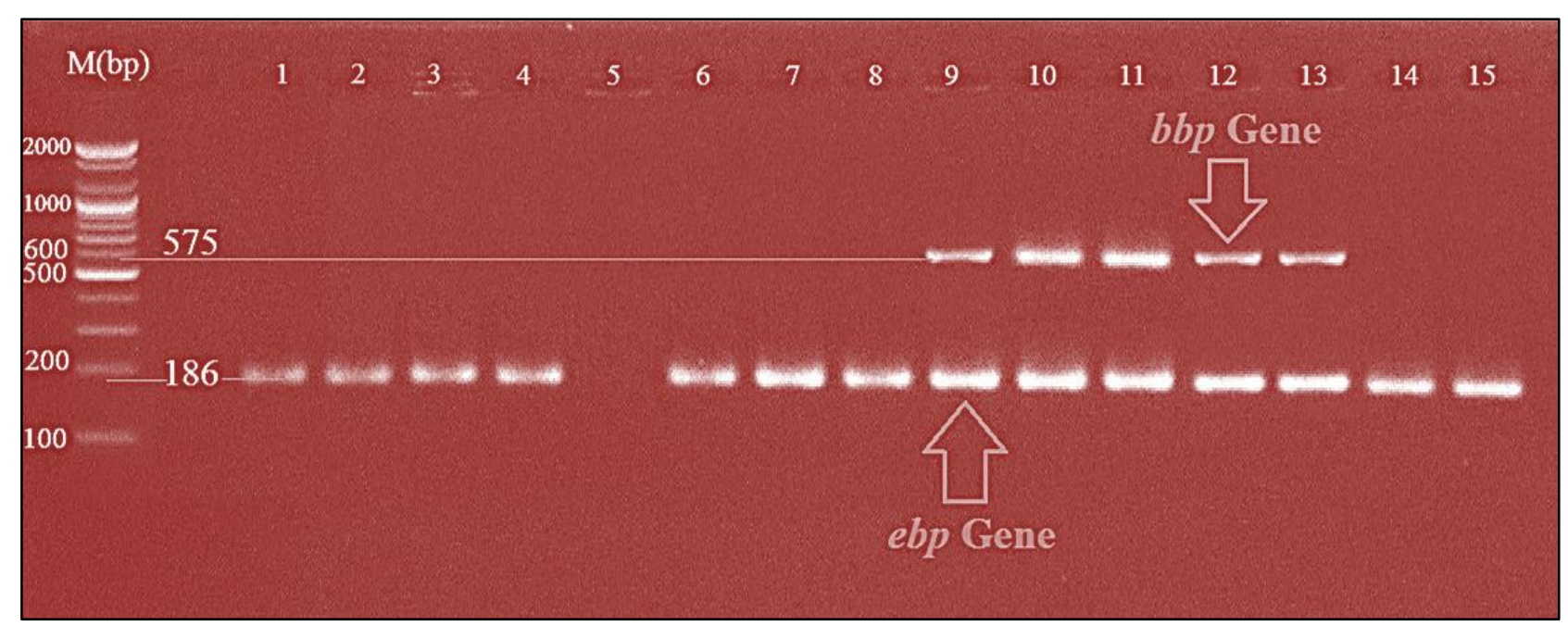

Fig.(6): Multiplex-PCR of (bbp and ebp) genes [1.5\% agarose, 1.5-2 $h$ and $70 \mathrm{~V}]$ with end product sizes: (575 and186) bp. Respectively; M: molecular weight marker; lanes 1-5: endocarditis isolates, 6-8: pneumonia isolates, 9-13: osteomyelitis isolates, 14 and 15: nasal isolates. 


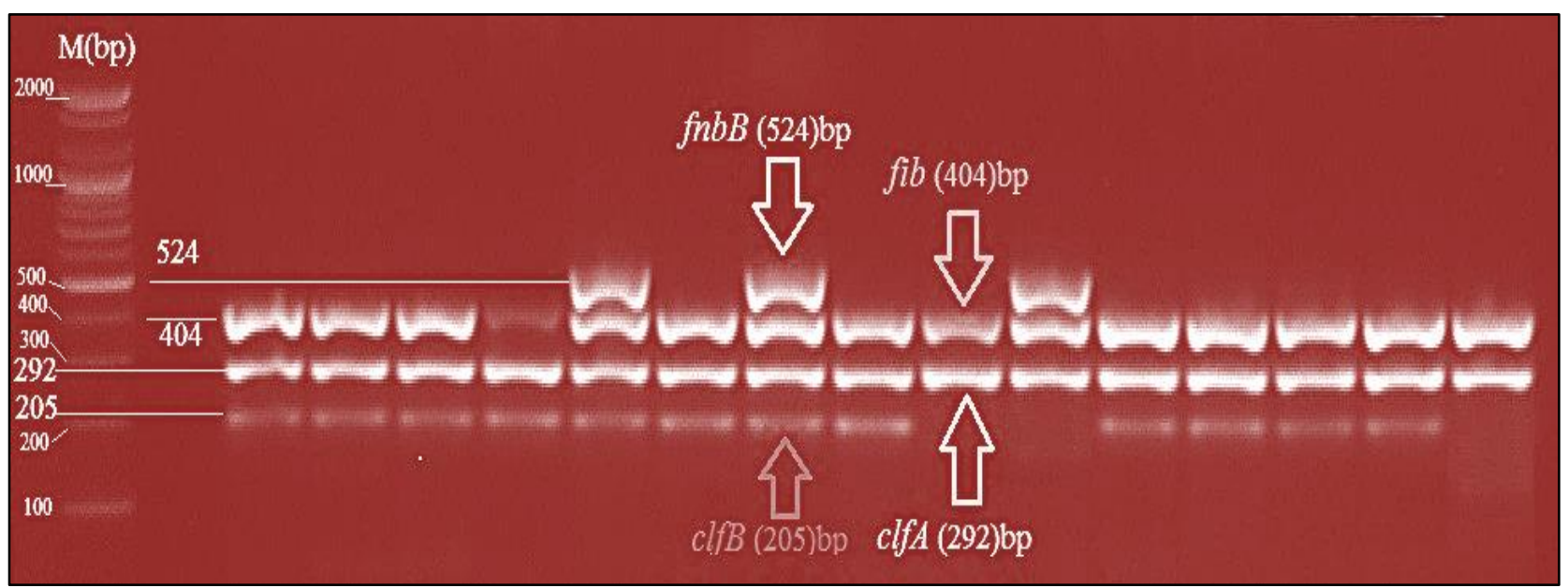

Fig.(7): Multiplex-PCR of ( fnbB, fib, clfA and clfB) genes [1.5\% agarose, 1.5-2 $\mathrm{h}$ and $70 \mathrm{~V}$ ] with end product sizes: (524, 404, 292 and 205bp. Respectively; M: molecular weight marker.

The prevalence of MSCRAMMs family genes is variant among different infections. clfA and clfB play important roles in $S$. aureus binding and colonization. In our study, clfA was detected in all isolates; $c l f B$ was found in (81.3)\%. The presence of clfA was related with all tested clinical infection, but $c l f B$ was related with all these infection except burn infections. Fibrinogen chains: $\gamma$ and $\alpha$ are the different action site that identified by ClfA and ClfB respectively (16). Thus, the presence of one gene from (clfA and clfB) is enough for binding $S$. aureus with its main receptor (fibrinogen). As a result, all isolates included in this study contain clumping activity.

The high prevalence of cna gene $(93.8 \%)$ in all infections sources is considered as an important factor to establishment of arthritis infections. All strains that have collagen binding protein ( $\mathrm{Cna}$ ) are capable of binding with cartilage (17). On the other hand, three bands kinds were detected in this study. The amplified fragment with size $617 \mathrm{bp}$ is the most frequent, where it appeared in 23 $(76.7 \%)$ isolates; band with size 1178 bp was found in $2(6.7 \%)$ isolates and the band with size 1739 bp was presented in $5(16.7 \%)$ isolates. Interestingly, all 3 types of bands were found in the different osteomyelitis isolates that mean the osteomyelitis isolates have varied development in cna gene. Also more than half $(60 \%)$ of carditis isolates were containing of type with size $1793 \mathrm{bp}$.

As an explanation of the variable product size of cna gene with using same primer pair, duplication of B (1-3) repeats (561 nucleotides) are the basic cause. Where the number of $\mathrm{B}$ region subunits depending on the strain origin (18). If we scrutinize in binding location of our cna primers pair on the oligonucleotide sequence "which was depended from Gene Bank- NCBI" of this gene with determination of position of each region from Patti et al., 1992 (19); we will find that the forward primer is complementary of location on one strand before $B$ region with 28 nucleotides and revers primer is binding in location on the other strand of the same gene after $\mathrm{B}$ region with 28 nucleotides. The final amplified nucleotides include $(28+28=56)$ bp and $B$ repeats (561 or 1122 or 1683) bp. Therefore if the $S$. aureus isolate contains only B1 in its cna gene structure, the end product size will be $617 \mathrm{bp}$. If the isolate contains B1 and $\mathrm{B} 2$ in its cna gene structure, the end product size will be $1178 \mathrm{bp}$. If the isolate contains B1, B2 and B3 in its cna gene structure, the end product size will be $1739 \mathrm{bp}$.

Moreover, B region of this protein structure isn't affecting on affinity activity of this protein, it acts as a stalk for A region; it donates the flexibility to affinity region (A region) (18). Therefore, the endocarditis isolates are the most isolates can express to highest flexibility Cna protein, but in the same time the variation of $\mathrm{B}$ repeats of cna gene in this study does not decrease detection of this gene with any above-mentioned sizes and an appearance of any band of these is enough to detect the genetic ability of the bacterial isolate to have this protein. 
FnbP A and B bind fibrinogen and fibronectin. They can also bind to elastin, which is crucial in attachment to connective tissue, they can capture plasminogen in plasma (20). In addition to that, the presence of $f n b A$ and $f n b B$ can increase the bacterial resistance to antibiotic agents by formation of biofilm (21). In this study, fnbA gene was found in all isolates of all infections unlike to $f n b B$ that found in one isolate of each studied infection. Thence $f n b B$ doesn't associate with specific infection. Therefore, the multifunction of Fnbps interprets the high distribution of $f n b A$ in all isolates without exception any infection source, that increase the pathogenicity of tested isolates in this study.

Both $f i b$ and $e b p$ genes are important for invasion of $S$. aureus. Therefore, detection of fib and ebp genes in (96.4\%) and (90.6\%) respectively increases the pathogenicity of tested isolates.

If we go far deep with isolates' sources, we can find: the endocarditis are associated with $c n a, f n b A, e b p$, fib, clfA and clfB. From axiomatic, the $e b p$ is most important for the heart colonization because an elastin protein found in heart's tissues and the blood vessels' walls (22). In addition to that, fnbA, fib, clfA and $c l f B$ are important for blood stream infections and associated with strains that infect cardiac devices and cause endocarditis (20). The cna gene also play a role in endocarditis. In spite of Vazquez et al., 2011 (23) reported that surface Bbp also binds human fibrinogen; but in our study $b b p$ gene didn't appear in any endocarditis isolates.

Osteomyelitis's isolates are the most virulent which contain: $c n a, f n b A, b b p, e b p$, $f i b, c l f A$ and $c l f B$. The $b b p$ gene was presented in all this infection isolates. Bone sialoprotein was previously described as a ligand of bone sialoprotein binding protein. In addition to that, cna gene is necessary to attach with collagenous proteins of bones (17). Those facts justify the containment of all osteomyelitis isolates of both these genes. Therefore, anti-bone sialoprotein binding protein can be used to prevent infection of bone by this bacterium especially with surgeries.

In nasal colonized isolates "which are collected from the outward healthy hospital workmen", cna, fnbA, , ebp, fib, clfA and clfB were found in these isolates. In Addition to that, one of these isolates $(25 \%)$ contained $f n b B$. Clumping factor $\mathrm{B}$ mediated colonization of epithelial cells in nose by binding with cytokeratin 10 (24). The presence of all these genes is very risky, which means an increase of infection opportunity among patients especially those who suffers from compromised immunity system.

Wounds, pneumonia and abscesses are similar in adhesion genes contribution to the nose isolates. Burns isolates associated with $c n a, f n b A$, ebp, fib, and $c l f A$; all of $b b p, c l f B$ and $f n b B$ weren't found in these isolates. All $c n a, f n b A, e b p, f i b, c l f A$ and $c l f B$ are necessary for epithelial cells, connective tissues, collagen, fibrin, fibrinogen, fibronectin and elastin attachment.

\section{Relationship among adhesive proteins genes distribution, isolates sources, biofilm formation and methicillin resistance}

The statistical analysis shown that only bbp gene "which encode bone sialoprotein binding protein" was statistically significantly associated with osteomyelitis infection ( $\mathrm{P}<$ 0.05). Ghasemian et al., 2015 (25) reported that $b b p$ gene was not detected in their isolates in Iran. this disagreement can be ascribed to the differentiation in infections sources of isolates and to variation of pathogenicity and virulence factor of isolates among different environments.

The $c l f B$ gene distribution was homogeneous among different sources except burns where $c l f B$ significantly lost in this source. The other MSCRAMM genes distribution did not differ among different infections sources $(\mathrm{P}<0.05)$.

There was no different distribution of these genes between biofilm former $S$. aureus isolates and non-biofilm former $S$. aureus isolates. Also no different distribution of MSCRAMMs genes between MRSA and MSSA strains $(\mathrm{P}<0.05)$, except for cna gene that significantly associated with MRSA strains $(\mathrm{P}<0.05)$ and $b b p$ was found only in MRSA strains without MSSA strains.

There is no relationship between biofilm production ability and MRSA or MSSA strains $(\mathrm{P}<0.05)$. 


\section{Conclusion}

Adhesive proteins (MSCRAMMs) genes have high prevalence among local $S$. aureus isolates; This high prevalence is very risky and important for novel vaccine production against $S$. aureus. clfA and fnbA genes are the most frequent genes $(100 \%)$ therefore, they can be used as a marker genes to detection local $S$. aureus. bbp gene is highly associated with osteomyelitis infection. High prevalence of MRSA strains among local S. aureus isolates, Imipenem and vancomycin are the most effect against $S$. aureus. The biofilm formation increases infection hardness to treat. Osteomyelitis isolates are the most virulent and the nasal isolates are the lowest. Finally, detection of nuc gene by PCR technique is optimal method for diagnosis of $S$. aureus with low cost which requires less time as compared with biochemical methods.

\section{Acknowledgment}

We are grateful to the laboratories staff in the hospitals: Ibn Al Bitar, Al Wasity, Al Yarmouk, Al-Nu'man, Baghdad and Educational laboratories in medical city for facilitate the collection of samples.

\section{References}

[1] Lowy F. D., "Staphylococcus aureus infections", The new england journal of medicine, 339 (8), 520-532, 1998, DOI: 10.1056/NEJM1998 08203390806

[2] Tong S. Y. C., Davis J. S., Eichenberger E., Holland T. L. and Fowler V. G. J. r., "Staphylococcus aureus infections: epidemiology, pathophysiology، clinical manifestations, and management", Clinical microbiology reviews, 28 (3), 603-660, 2015, DOI: 10.1128/CMR.00134-14.

[3] Vengadesan K. and Narayana S., "Structural biology of gram-positive bacterial adhesins", Protein science, 20, 759-772, 2011, DOI: 10.1002/pro.613.

[4] Stones D. H. and Krachler A. M., "Fatal attraction: how bacterial adhesins affect host signaling and what we can learn from them", International journal of molecular sciences, 16 (2), 2626-2640, 2015, DOI:10.3390/ijms 16022626.

[5] Speziale P., Pietrocola G., Foster T. J. and Geoghegan J. A., "Protein-based biofilm matrices in staphylococci", Frontiers in cellular and infection microbiology, 4, 171, 2014, DOI: 10.3389/fcimb.2014.00171.

[6] Provenza G., Provenzano M., Visai L., Burke F. M., Geoghegan J. A., Stravalaci M., Gobbi M., Mazzini G., Arciola C. R., Foster T. J. and Speziale P., "Functional analysis of a murine monoclonal antibody against the repetitive region of the fibronectin-binding adhesins fibronectinbinding protein $\mathrm{A}$ and fibronectin-binding protein B from Staphylococcus aureus", FEBS journal, 277 (21), 4490-505, 2010, DOI: 10.1111/j.1742-4658.2010.07835.x.

[7] Bauer A. W., Kirby W. M. M., Sherris J. C. and Turck M. "Antibiotic Susceptibility Testing by a Standardized Single Disk Method", The American journal of clinical pathology, 45 (4), 493-496, 1966.

[8] CLSI. Clinical and Laboratory Standards Institute, Performance Standards for Antimicrobial Susceptibility Testing, Eleventh edition, 2012.

[9] Christensen G., Simpson W. A., Younger J. J., Baddour L. M., Barrett F. F., Melton D. M. and Beachey E.H., "Adherence of Coagulase-Negative Staphylococci to plastic tissue culture plates: a quantitative model for the adherence of Staphylococci to medical devices", Journal of clinical microbiology, 22 (6), 996-1006, 1985.

[10] Peacock S. J., Moore C. E., Justice A., Kantzanou M., Story L., Mackie K., O'Neill G. and Day N. P. J., "Virulent combinations of adhesin and toxin genes in natural populations of Staphylococcus aureus", Infection and immunity, 70 (9): 4987-4996, 2002, DOI: 10.1128/IAI.70.9.4987-4996.2002.

[11] Tristan A., Ying L., Bes M., Etienne J., Vandenesch F. and Lina G., "Use of multiplex PCR to identify Staphylococcus aureus adhesins involved in human hematogenous infections", Journal of clinical microbiology, 41 (9), 4465-4467, 2013, DOI: 10.1128/JCM.41.9.4465-4467. 2003.

[12] Karmakar A., Dua P. and Ghosh C., "Biochemical and molecular analysis of Staphylococcus aureus clinical isolates from hospitalized patients", Canadian journal of infectious diseases and medical 
microbiology, 9041636, 2016, DOI: 10.1155/2016/9041636.

[13] Coelho S. M. O., Menezes R. A., Soares L .C., Pereira I. A., Gomes L. P. and Souza M. M. S, "Mapeamento do perfil de resistência e detecção do gene mecA em Staphylococcus aureus e Staphylococcus intermedius oxacilina-resistentes isolados de espécies humanas e animais", Ciência rural, 37 (1), 195-200, 2007.

[14] Blair J. M. A., Webber M. A., Baylay A. J., Ogbolu D.O. and Piddock L. J. V., "Molecular mechanisms of antibiotic resistance", Nature reviews microbiology, $13 \quad(1), \quad 42-51, \quad 2015$, DOI: 10.1038/nrmicro3380.

[15] Mason W. J., Blevins J. S., Beenken K., "Multiplex PCR protocol for the diagnosis of staphylococcal infection", Journal of clinical microbiology, 39, 3332-3338, 2001, DOI: 10.1128/JCM.39.9.3332-3338.2001.

[16] Flick M. J., Du X., Prasad J. M., Raghu H., Palumbo J. S., Smeds E., Hook M. and Degen J. L, "Genetic elimination of the binding motif on fibrinogen for the $S$. aureus virulence factor ClfA improves host survival in septicemia", Blood, 121(10), 1783-1794, 2013, DOI:10.1182/blood2012-09-453894.

[17] Josse J., Velard F. and Gangloff S. C., "Staphylococcus aureus vs. osteoblast: relationship and consequences in osteomyelitis", Frontiersin cellular and infection microbiology, 5 (85), 2015, DOI: 10.3389/fcimb.2015.00085.

[18] Deivanayagam C. C. S., Rich R. L., Carson M., Owens R. T., Danthuluri S., Bice T., Hook M. and Narayana S. V. L., "Novel fold and assembly of the repetitive B region of the Staphylococcus aureus collagen-binding surface protein", Structure, 8 (1), 67-78, 2000.

[19] Patti J. M., Jonsson H., Guss B., Switalskill L. M., Wiberg K., Lindberg M. and Hook M., "Molecular characterization and expression of a gene encoding a Staphylococcus aureus collagen adhesion", The journal of biological chemistry, 267 (7), 4766- 4772, 1992.
[20] Foster T. J., "The remarkably multifunctional fibronectin binding proteins of Staphylococcus aureus", European journal of clinical microbiology and infectious diseases, 35 (12), 1923-1931, 2016, DOI:10.1007/s10096-016-2763-0.

[21] McCourt J., O’Halloran D. P., McCarthy H., O'Gara J. P. and Geoghegan J. A., "Fibronectin-binding proteins are required for biofilm formation by community-associated methicillin-resistant Staphylococcus aureus strain LAC", FEMS microbiology letter, 353, 157-164, 2014, DOI: $10.1111 / 1574-6968.12424$.

[22] Halm M., Schenke-Layland K., Jaspers S., Wenck H. and Fischer F., "Visualizing tropoelastin in a longterm human elastic fibre cell culture model", Scientific reports, 6, 20378, 2016, DOI: 10.1038/srep20378.

[23] Vazquez V., Liang X., Horndahl J. K., Ganesh V. K., Smeds E., Foster T. J. and Hook M., "Fibrinogen is a ligand for the Staphylococcus aureus microbial surface components recognizing adhesive matrix molecules (MSCRAMM) bone sialoproteinbinding protein (bbp)", The journal of biological chemistry, 286 (34), 29797-29805, 2011, DOI: 10.1074/jbc.M110.214981.

[24] Liu G. Y., "Molecular pathogenesis of Staphylococcus aureus infection", Pediatric research, 65 (5 Pt 2), 71-77, 2009, DOI: 10.1203/PDR.0b013e31819dc44d.

[25] Ghasemian A., Peerayeh S. N., Bakhshi B. and Mirzaee M, "The microbial surface components recognizing adhesive matrix molecules (MSCRAMMS) genes among clinical isolates of Staphylococcus aureus from hospitalized children" Iran journal of pathology, 10 (4), 258-264, 2015. 